\title{
VALORIZAÇÃO DOS PRODUTOS ORIUNDOS DO RESIDUO DE COURO WET-BLUE HIDROLISADO
}

\section{VALUATION OF PRODUCTS FROM WET-BLUE HYDROLYZED LEATHER WASTE}

\author{
Márcio Rosa 0244159@feevale.br \\ Mestre em Tecnologia dos materiais e processos industriais pela universidade Feevale \\ (Novo Hamburgo/Brasil).
}

\section{Vanusca Dalosto Jahno vanusca@feevale.br}

Doutora em Medicina e Ciências da Saúde pela Pontifícia Universidade Católica do Rio Grande do Sul (Porto Alegre/Brasil). Professora e pesquisadora na Universidade Feevale (Novo Hamburgo/Brasil). Bolsista de Produtividade Desen. Tec. e Extensão Inovadora do CNPq - Nível 2

\section{Patrice Monteiro de Aquim patrice@feevale.br}

Doutora em Engenharia Química pela Universidade Federal do Rio Grande do Sul (Porto

Alegre/Brasil). Professora e pesquisadora na Universidade Feevale (Novo Hamburgo/Brasil).
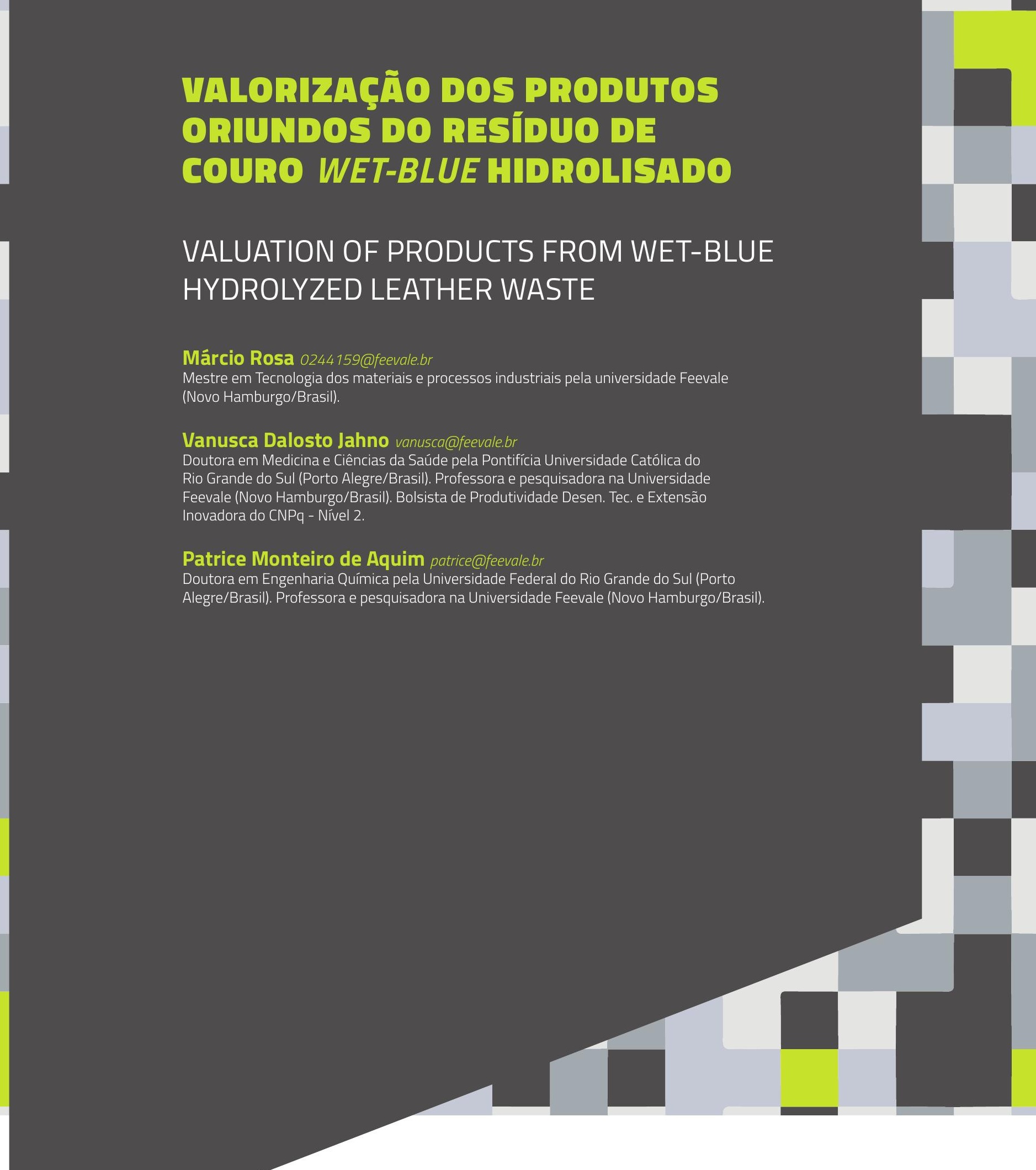

RT\&T | a. 11 | n. 1 | p. 90-111 | jan./jun. 2020

Recebido em: 3 de agosto de 2019| Aprovado em: 14 de dezembro de 2019 Sistema de Avaliação: Double Blind Review | DOI: https://doi.org/10.25112/rtt.v11i1.2280 


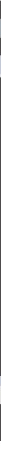

\section{RESUMO}

O processo de transformação de pele em couro gera um expressivo volume de efluente, emissões atmosféricas e de resíduos sólidos. Dependendo dos insumos e principalmente do curtente utilizado, o curtimento pode gerar resísuos perigosos. É o caso dos processos que utilizam o óxido cromo como curtente. Estima-se que 90\% dos curtumes utiliza o óxido de cromo em função do seu custo benefício. Visando reduzir o envio de resíduo de couro wet-blue para aterros de resíduos perigosos, este trabalho tem como objetivo propor um método que permite reduzir a concentração de cromo do resíduo. 0 estudo compreendeu as seguintes etapas: 1) caracterização físico-química do resíduo wet-blue; 2) testes de hidrólise em fulões piloto com emprego de ácido cítrico, variando relação cromo:ácido, pH e método de lavagem; 3) caracterização físico química do colágeno hidrolisado e do banho residual do processo de hidrólise. Os resultados obtidos revelaram que a hidrólise com ácido cítrico possibilitou uma redução de até $87,35 \%$ do cromo presente no resíduo de wet-blue e resultou na geração de dois produtos: um material sólido colagênico rico em nitrogênio e com potencial de ser utilizado como fonte de nutrientes para plantas, como matéria prima para produção de adesivo ou adsorvente, e um efluente de coloração escura com pH baixo e com aproximadamente $500 \mathrm{mg} \cdot \mathrm{Cr}_{\text {. }}{ }^{-1}$ com possibilidade de ser reaproveitado no processo de curtimento. Assim, o estudo demonstrou uma alternativa tecnológica para o tratamento de resíduos de wetblue, possibilitando o reaproveitamento de materiais que seriam descartados em aterros de resíduos perigosos.

Palavras-chave: Descromagem. Hidrólise Ácida. Resíduo de Couro.

\section{ABSTRACT}

The process of transforming skin into leather generates a significant volume of effluent, atmospheric emissions and solid waste. Depending on the inputs and mainly the tanner used, tanning can generate dangerous residues. This is the case of processes that use chromium oxide as a tanner. It is estimated that $90 \%$ of tanneries use chromium oxide due to its cost benefit. Aiming to reduce the shipment of wet-blue leather waste to hazardous waste landfills, this work aims to propose a method that allows reducing the chromium concentration of the waste. The study comprised the following steps: 1) physical chemical characterization of wet-blue waste; 2 ) hydrolysis tests on pilot drums using citric acid, varying the chromium: acid ratio, $\mathrm{pH}$ and washing method; 3) physical and chemical characterization of the hydrolyzed collagen and the residual bath of the hydrolysis process. The results obtained revealed that the hydrolysis with citric acid allowed a reduction of up to $87.35 \%$ of the chromium present in the wet-blue residue and resulted in the generation of two products: a solid collagen material rich in nitrogen and with the potential to be used as source of nutrients for plants, as raw material for the production of adhesive or adsorbent and a dark colored effluent with low pH and approximately $500 \mathrm{mg}$.Cr.L-1 with the possibility of being reused in the tanning process. Thus, the study demonstrated a technological alternative for the treatment of wet-blue waste, enabling the reuse of materials that would be disposed of in hazardous waste landfills.

Keywords: Acid Hydrolysis. Decromatization. Leather residue. 


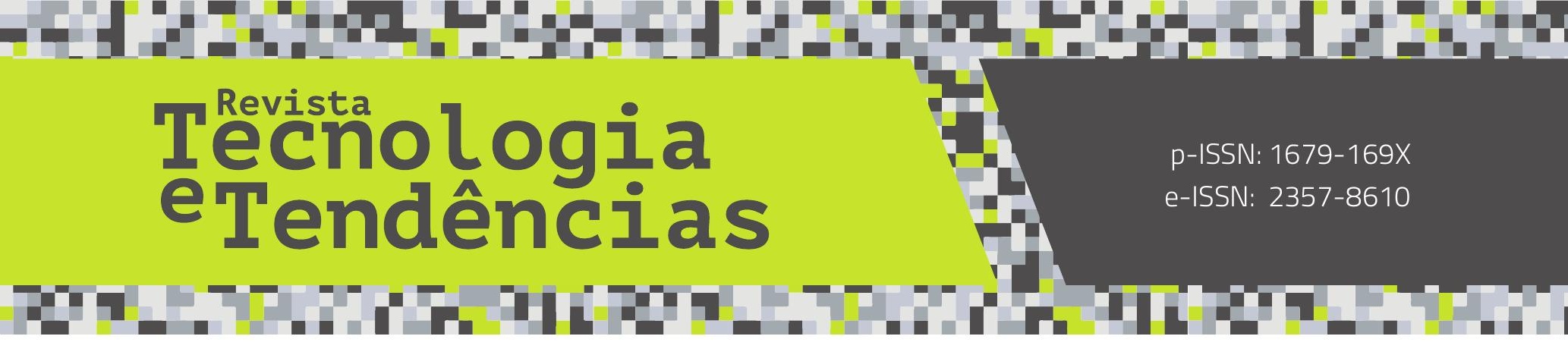

\section{INTRODUÇÃO}

O Brasil está entre os maiores beneficiadores de couro do mundo, o segmento é composto por mais de 310 curtumes e tem um papel relevante do ponto de vista econômico, movimentando mais de 3 bilhões de dólares por ano e exportando para mais de 80 países, social, empregando mais de 40 mil pessoas, e ambiental, sendo responsável por geração de um expressivo volume de resíduos (CICB, 2017). Na transformação das peles em couros, 40\% do material curtido é perdido em forma de resíduos sólidos (ABREU, 2006), o rejeito curtido ao cromo é classificado pela ABNT como resíduo perigoso (NBR 10004, 2004). Estima-se que 90\% dos curtumes utilizem o óxido de cromo como curtente em função do seu baixo custo e das características que o mesmo confere ao couro (SCOPEL, et al., 2018; BACARDTI, et al., 2015).

O processo de descromagem é apontado como solução para o gerenciamento sustentável dos resíduos de couro, por ser capaz de viabilizar a extração do cromo preservando o colágeno e permitindo com isso agregar valor aos produtos obtidos (GARCIA, 2015). Autores como Longui (2018), Scopel (2018) e Oliveira (2007) realizaram a descromagem do farelo de wet-blue utilizando a hidrólise como técnica para extrair o cromo e aproveitar o colágeno.

Os trabalhos referidos apontam soluções para a transforação do wet-blue em matéria prima para a produção de produtos como fertilizantes, adesivo, adsorvente, no entanto, foram testados apenas em escala de bancada. Diante deste contexto, o presente trabalho tem como objetivo propor uma descromagem de resíduo wet-blue por meio de hidrólise ácida em fulões piloto de curtume utilizando o ácido cítrico como agente de extração.

\section{FUNDAMENTAÇÕES TEÓRICAS}

\subsection{GERENCIAMENTO DE RESÍDUOS SÓLIDOS}

Quando a geração de um resíduo perigoso é inevitável e sua reciclagem e/ou reúso é inviável, os rejeitos geralmente são dispostos em aterros industriais que, além de gerar custos para disposição (RIEHL, 2015), tornam as áreas ocupadas impróprias para usos nobres por longos períodos.

Mediante o exposto e acrescentando-se a necessidade de atendimento à Política Nacional de Resíduos Sólidos, por meio de uma gestão que prioriza a redução do volume e da periculosidade dos resíduos (BRASIL, 2010), emerge a necessidade de produzir alternativas que permitam transformar o resíduo sólido em um bem econômico e de valor social, gerador de trabalho e de renda (SIMIONI; DETMER, 2014). 


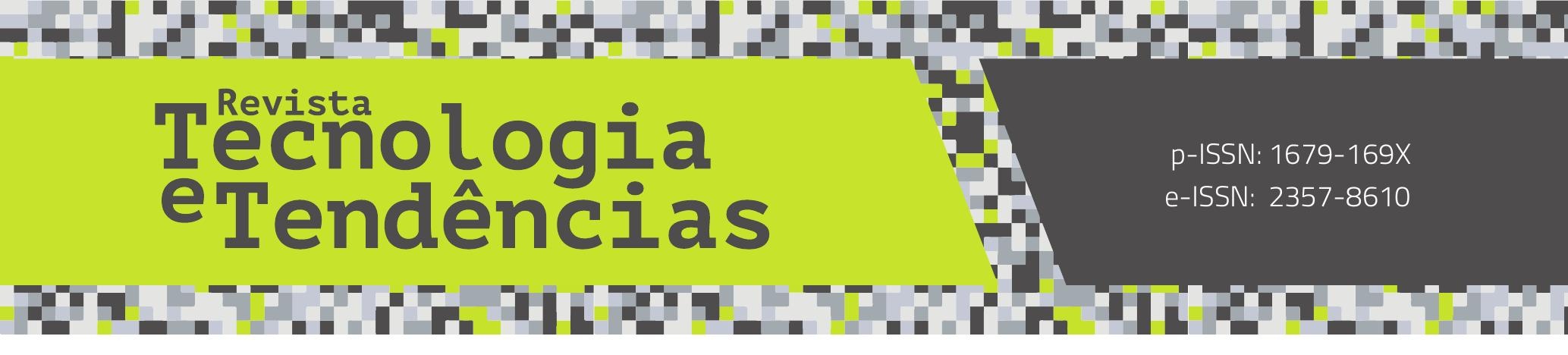

Alinhado a este pensamento, Metz (2016) acredita que se pode considerar que os resíduos gerados na transformação de pele em couro podem resultar em subprodutos ou coprodutos, desde que haja um aprimoramento no processo, focando na valorização econômica dos resíduos sólidos da indústria curtidora.

\subsection{PROCESSOS DE REAPROVEITAMENTO DO RESÍDUO DE COURO}

Segundo Cabeza (1998), entre 1969 e 1988, pesquisadores publicaram métodos de descromagem para recuperação do colágeno e do cromo (BROW, 1986; COT et al., 1986), por meio do emprego técnicas que utilizam ácidos, bases ou enzimas que propiciam a ruptura de ligações, dissociando o cromo do colágeno sem destruir as propriedades das fibras, possibilitando agregar valor aos produtos obtidos no processo (SCOPEL et al., 2018; SUNDAR et al., 2011).

$\mathrm{Na}$ estrutura proteica da pele, o cromo faz ligações com oxigênio e com os grupos carboxila do colágeno (MALEK et al., 2009), assim, para realizar a descromagem, é necessário que essas ligações sejam desestabilizadas ao ponto de provocar a ruptura entre as mesmas (GARCIA, 2015).

O processo de hidrólise ácida, básica ou enzimática apresenta-se como uma das técnicas possíveis para promover a reação de decomposição ou alteração de uma substância pela ação da água ou de um fluído aquoso. A reação ocorre com íons de hidrogênio $\left(\mathrm{H}^{+}\right)$ou de hidroxila $\left(\mathrm{OH}^{-}\right)$, substituindo íons que são liberados para a solução e possibilita a quebra de cadeias polipeptídicas em pequenos fragmentos peptídicos ou em aminoácidos (AMARAL, 2008).

O emprego da hidrólise em resíduos de couro curtido ao cromo viabiliza a extração de duas frações principais: o resíduo perigoso (cromo) e a proteína (colágeno) (SCOPEL, et al., 2018).

Entre os produtos produzidos a partir de descromagem com uso da hidrólise pode-se citar: revestimentos (CABEZA et al., 1999); agentes de recurtimento (TAHIRI et al., 2004; BROW, 1986), adesivos, produção de filmes (COT et al., 1999, SCOPEL, 2016); alimentação animal (SILVA et al., 2009) e fertilizantes (LONGHI, 2018; COELHO, 2015; OLIVEIRA, 2007).

É importante destacar que o produto hidrolisado está diretamente relacionado com a composição do resíduo utilizado, sendo, portanto, indispensável caracterizar o resíduo para ajustar o processo aos resultados almejados (SCOPEL et al., 2018). Para tanto, de acordo com Scopel (2018), a introdução de resíduos oriundos de diferentes processos pode dificultar a reprodutividade da técnica ao ponto de gerar resultados que podem ser melhores ou piores aos obtidos anteriormente. Segundo Mokrejs et al. (2007), o custo de produção de hidrolisados de proteína não é desprezível, e a aplicação deste processo na indústria depende mais da viabilidade econômica do que técnica. 


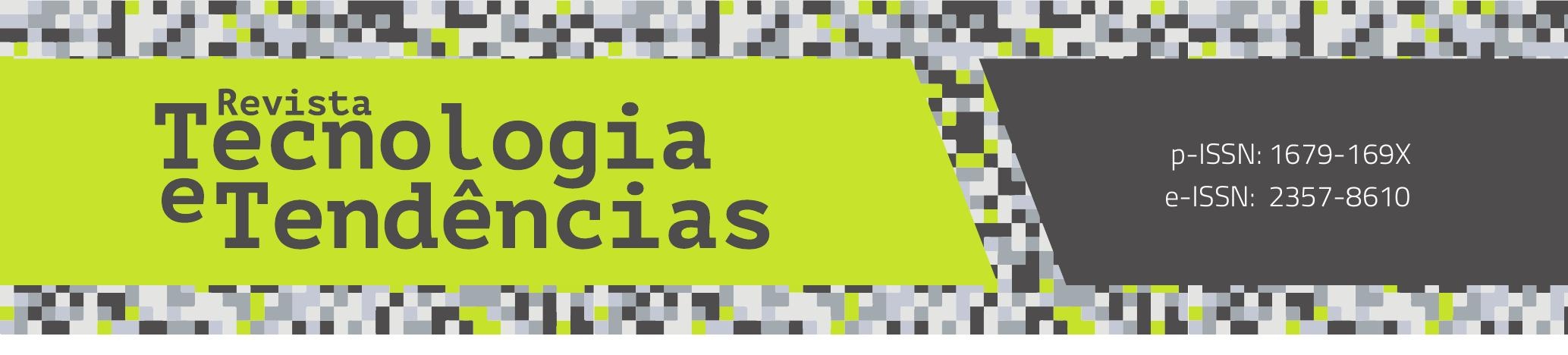

Atualmente são empregados três principais processos de hidrólise: ácido, básico e enzimático que serão descritos nos tópicos a seguir.

\subsubsection{Hidrólise Enzimática}

As enzimas foram descobertas por Spallanzan em 1783, ao observar a degradação enzimática da carne pelo suco gástrico. Em 1814, foi Kirchoff que percebeu que a proteína da cevada era capaz de liquefazer o amido em açúcar - técnica que até hoje é utilizada em cervejaria e que foi batizada, em 1833, por Payen e Persoz, de diástase (COELHO, 2008).

Para Silva e Pfeiter (2005), enzimas são proteínas solúveis em água, álcool e glicerina e funcionam como catalisadoras das reações químicas e bioquímicas, acelerando e facilitando a condução cinética das mesmas. Segundo Amaral (2008), enzimas são proteínas catalisadoras que promovem reações químicas nos sistemas biológicos, sendo sintetizadas termodinamicamente em células vivas, de modo que a velocidade da reação seja compativel com o processo bioquímico essencial para manter a célula.

Taylor et al. (1998) desenvolveram um estudo utilizando a enzima ALCALASE ${ }^{\circledR}$ da marca Novozymes, com objetivo de isolar produtos proteicos de serragens cromadas, para posteriormente curtir peles com este cromo. Os autores demonstraram ser possivel o isolamento da gelatina e da torta de cromo.

Kolomaznik et al. (2000) desenvolveram um processo para tratamento enzimático de resíduos de couro cromados, utilizando aminas orgânicas para basificar o meio, e a enzima proteolítica ALCALASE ${ }^{\circledR}$ 2 5LDX produzida pela Novozymes. Os experimentos obtiveram êxito na separação das proteínas e do cromo.

O estudo de Ribeiro (2003) utilizou a enzima Novocor SG para promover uma hidrólise enzimática. Ao fim do experimento, obteve-se uma solução proteica com baixo teor de cromo e uma torta sólida remanescente contendo cromo que pode ser reaproveitado para o curtimento de peles. 0 estudo de Ribeiro (2003) apontou que a granulometria, o tempo, a temperatura e a concentração de reagentes possuem influência sob o resultado do experimento. Os melhores resultados foram obtidos com o resíduo cominuído, utilizando-se $8 \%$ de hidróxido de cálcio como basificante por 60 minutos e com emprego de $10 \%$ de enzimas por cinco horas de incubação em uma temperatura de $60 \mathrm{C}$.

Amaral (2008), por sua vez, utilizou a enzima P-555 (Buckman Laboratories) para desenvolver a hidrólise enzimática. $O$ processo foi conduzido usando temperatura de $60^{\circ} \mathrm{C}, \mathrm{pH} 9,0$, tempo de basificação de uma hora, tempo de incubação de três horas e concentração de enzima em relação à massa inicial de amostra igual a $10 \%$. Ao final do experimento obtiveram-se dois produtos: 1) um líquido proteico com potencial de ser utilizado como fertilizante para fabricação de adesivos ou no recurtimento de couros; 2 ) uma torta de cromo com potencial de ser recuperado como sal recurtente. 


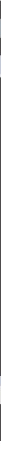

Segundo a literatura, a hidrólise enzimática geralmente é realizada em dois passos: o primeiro consiste em um pré-tratamento químico, seguido pela adição de enzima onde inicialmente se obtém a gelatina. Após a adição da enzima é produzido o colágeno hidrolisado (SCOPEL, et al., 2018). Os processos envolvendo enzimas apresentam geralmente uma maior extração de proteína. Em contrapartida, apresentam custo mais elevado e maior emprego de agentes químicos (KOLOMAZNIK et al., 2000).

Em geral, a digestão enzimática de aparas de couro resulta em uma proteína gelatinizável e um lodo contaminado com cromo. $\mathrm{O}$ hidrolisado pode ser utilizado em agentes recurtentes, enquanto que o lodo contendo cromo pode ser reutilizado em uma planta de redução de dicromato para produção de sulfato de cromo (AMARAL, 2008). Fábricas de processamento enzimático de resíduos cromados estão em operação nos Estados Unidos e na República Tcheca, mostrando que o processo é viável (AMARAL, 2008).

\subsubsection{Hidrólise Alcalina}

Assim como na hidrólise ácida, diversos estudos foram e vêm sendo realizados para a remoção do cromo do resíduo wet-blue por meio de hidrólise alcalina. Os estudos demonstram a influência de variáveis como: agentes basificantes, relação cromo:base, tempo de reação, temperatura, pressão, granulometria e pH (MÄHLER, 1999; COT et al., 1999; OLIVEIRA, 2007; SCOPEL et al., 2018).

Mähler (1999) realizou experimentos de descromagem alcalina com adição de peróxido de hidrogênio ou perborato de sódio, variando a concentração de basificante, granulometria do resíduo, temperatura, pressão e tempo de processo. 0 perborato de sódio apresentou melhor desempenho que o peróxido de hidrogênio. A proteína apresentou um teor residual médio de 237 mg.kg-1 de cromo.

Cot et al. (1999) removeram o cromo do resíduo de wet-blue através de hidrólise alcalina com a ação de peroxocromatos, convertendo o $\mathrm{Cr}^{+3}$ para $\mathrm{Cr}^{+6}$. Segundo o autor, a formação de peroxocromatos permite o isolamento da proteína, produzindo uma gelatina de boa qualidade.

Oliveira (2007) realizou estudos testando reações de hidrólise com bases ( $\mathrm{NaOH}$ e $\mathrm{KOH}$ ); razão molar (cromo: base) 1:1; 1:1,5 e 1:2; tempo 1, 2 e 3 horas e temperatura $60^{\circ} \mathrm{C}$ e $70{ }^{\circ} \mathrm{C}$. 0 hidróxido de sódio apresentou o melhor resultado, com extração de $98,8 \%$ do cromo III nas condições: razão (cromo:base) $1: 2$; temperatura $70^{\circ} \mathrm{C}$ e tempo de 1 hora.

Scopel et al. (2016) promoveram estudos de hidrólise alcalina utilizando o óxido de cálcio e de magnésio para reaproveitamento do colágeno como fertilizante. 0 experimento variou a proporção wet-blue: alcalinizante entre $1: 2$ e 1:8; temperatura entre $55^{\circ} \mathrm{C}$ e $70^{\circ} \mathrm{C}$, tempo entre 4 horas e 6 horas e velocidade de agitação entre 180 rpm e 280 rpm. A condição ótima de extração ocorreu quando proporções de $2 \mathrm{~g}$ de $\mathrm{MgO}$ para cada $50 \mathrm{~g}$ de wet-blue e $250 \mathrm{~mL}$ de água foram submetidas a $6 \mathrm{~h}$ de hidrólise a $70^{\circ} \mathrm{C}$ e frequência de agitação de 180rpm. 0 produto final apresentou 2,2g/L de Nitrogênio e teor de cromo < 0,04mg/L. 


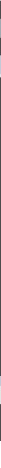

Na hidrólise alcalina, o colágeno (gelatina) hidrolisado apresenta baixo teor de cromo, pois em valores de $\mathrm{pH}$ elevado, o cromo precipita como $\mathrm{Cr}(\mathrm{OH})_{3}$. O hidrolisado alcalino é produzido em condições mais agressivas que o hidrolisado ácido, pois, geralmente, exige temperatura e $\mathrm{pH}$ mais elevados - o que pode resultar na degradação da proteína (CABEZA, et al., 1999).

Os estudos com Hidrólise alcalina evoluiram para um projeto em escala conduzido pelo Centro Tecnológico da Associación de Investigación de las Industrias del Curtido y Anexas (AllCA, 2006), da Espanha, que teve como objetivo a conversão de serragens de couro wet-blueem fertilizantes, cosméticos, alimentação animal, tensoativo, matéria-prima para indústria química, entre outra.

\subsubsection{Hidrólise Ácida}

A primeira utilização da hidrólise ácida para remoção do cromo da serragem de rebaixadeira ocorreu na Segunda Guerra Mundial, quando pesquisadores alemães descurtiram a serragem com ácido lático, separando o cromo e a pele para utilização da gelatina para alimentação humana (SPIER; WESTHAUSER, 1994 apud HIJAZI, 2003).

A extração de cromo com o uso de hidrólise ácida vem sendo testada por vários autores com o emprego de diferentes ácidos e com variáveis como: relação cromo:ácido, tempo de reação, temperatura do banho, granulometria, velocidade de agitação e pH (BROWN, 1986; HIJAZI, 2003; BRUNS, 2004 ; OLIVEIRA, 2007; LONGHI, 2018).

Os estudos e autores a seguir apontam as aplicações destas variáveis e demonstraram que foi possível obter resultados de extração do cromo, que variaram de 60\% a 99\%. Brown et al. (1986) realizaram estudos de extração do cromo por hidrólise de resíduos de couro utilizando ácidos hidroxâmicos, conhecidos pela característica de formar complexos solúveis ou insolúveis. A hidrólise foi realizada em uma solução aquosa a 2\% de ácido por um período de 36 horas. 0 ácido benzohidroxâmico apresentou os melhores resultados com extração de $91 \%$ do $\mathrm{Cr}^{3+}$.

Brown (1986) realizou hidrólise com ácido cítrico para extração do cromo do resíduo de rebaixadeira nas seguintes condições de operação: $\mathrm{pH} 6$, temperatura de $70^{\circ} \mathrm{C}$, tempo de 3 h e razão molar (Cr:Ligante) 1:4. 0 percentual de extração de cromo obtido pelo autor foi de $87 \%$.

Hijazin (2003) realizou experimentos para extração de cromo de resíduo de rebaixadeira com emprego de ácidos orgânicos. 0 autor comparou a ação dos ácidos: cítrico, Etilenodiaminotetracético (EDTA sódico) e 2,6-piridinadicarboxílico (2,6-PDC). 0 experimento analisou a influência dos ácidos associados às variáveis tempo 1 hora e 3 horas, razão molar (cromo:ligante) 1:1 e 1:4, temperatura $50{ }^{\circ} \mathrm{C}$ e $70{ }^{\circ} \mathrm{C}$; pH 5 e pH 7. 0 ácido cítrico apresentou uma extração de $87,27 \%$ do cromo nas condições: razão molar (cromo:ligante) $1: 4, \mathrm{pH} 7$, temperatura de $70^{\circ} \mathrm{C}$ e tempo de $3 \mathrm{~h}$. 


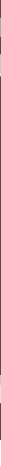

Bruns (2004) realizou a extração de cromo do resíduo de couro cromado à frio, com ácido cítrico na concentração $1 \mathrm{M}$, relação de banho $1 \mathrm{~g}$ de couro para $25 \mathrm{~mL}$ de solução ácida e 48 horas de agitação. 0 percentual de extração de cromo III obtido no processo foi de aproximadamente $60 \%$.

Oliveira (2007) realizou estudos testando reações de hidrólise com ácidos $\mathrm{HCl}, \mathrm{H}_{2} \mathrm{SO}_{4^{\prime}} \mathrm{H}_{3} \mathrm{PO}_{4^{\prime}}$; razão molar (cromo:ácido) 1:1; 1:1,5 e 1:2; tempo 1, 2 e 3 horas e temperatura $25^{\circ} \mathrm{C}, 40{ }^{\circ} \mathrm{C}, 50^{\circ} \mathrm{C}, 60^{\circ} \mathrm{C}, 70^{\circ} \mathrm{C}$ e $80^{\circ} \mathrm{C}$. 0 ácido fosfórico foi o reagente que apresentou o melhor resultado, nas condições: razão molar (cromo:ácido) 1:1, temperatura de $70^{\circ} \mathrm{C}$, tempo de 2 horas, obteve-se uma extração de $99,6 \%$ do cromo III do resíduo de wet-blue.

Longhi (2018) também promoveu um estudo de hidrólise com uso de ácidos orgânicos com o objetivo de desenvolver um substrato contendo nutrientes retirados de resíduos de couro wet-blue para utilização como adubo para plantas. A autora comparou a ação do ácido malêico e do ácido cítrico. 0 processo utilizou uma razão (couro/ácido) de 1:3, temperatura de $55{ }^{\circ} \mathrm{C}$ e tempo de 3 horas. 0 ácido cítrico mostrou-se mais efetivo promovendo uma extração de $95 \%$ do cromo III.

Dentre os diferentes agentes para promoção da hidrólise, a escolha do ácido cítrico se deu em função das caracterísricas do agente, como: ser natural, atóxico, biodegradável e barato.

\section{METODOLOGIAS}

O esquema experimental executado neste trabalho está ilustrado na Figura 1.

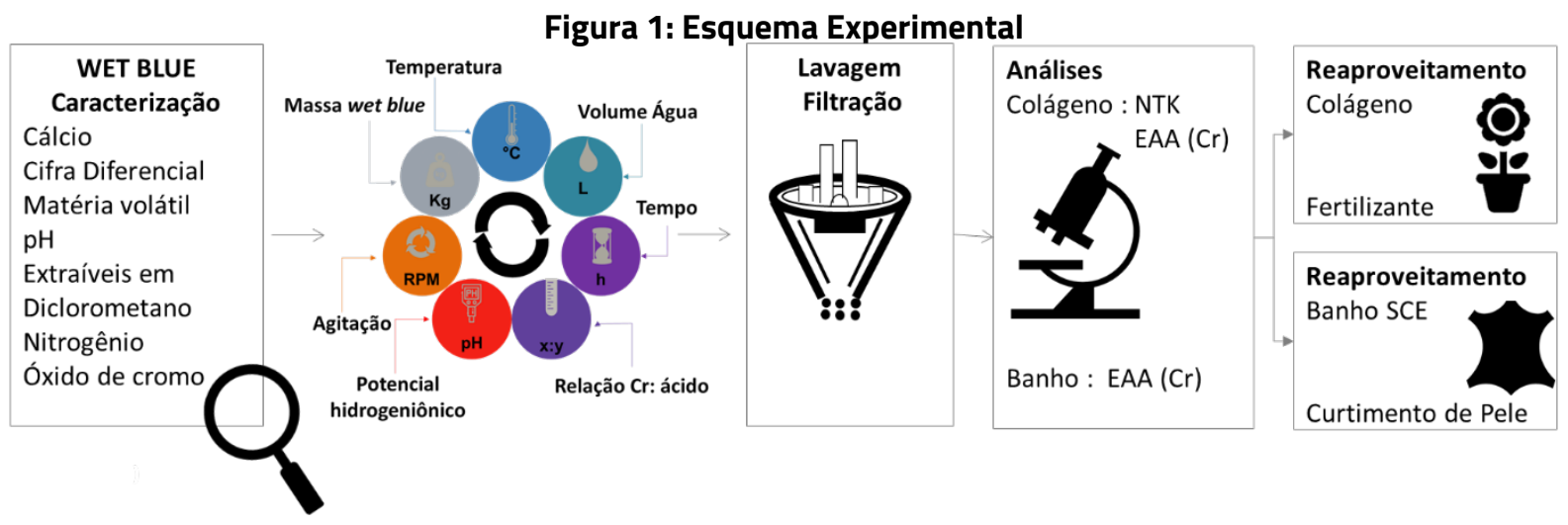

Legenda: NTK Nitrogênio de Kjeldahl Total; EAA espectrofotômetro de absorção atômica;

SCE - Solução de cromo extraído (banho do hidrolisado).

Fonte: Autor (2020)

O experimento compreendeu as seguintes etapas: 1) caracterização e aparas de couro curtido ao cromo por meio de análises fisico-químicas; 2 ) ensaio piloto da hidrólise em fulões com emprego de ácido 


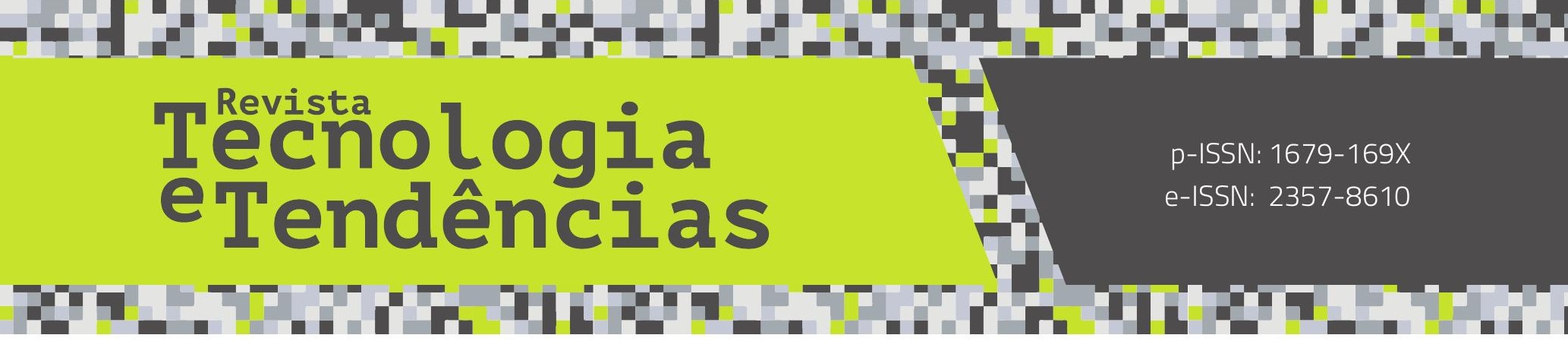

cítrico; 3) caracterização do colágeno hidrolisado e da solução de cromo extraído (SCE). Estas etapas estão detalhadas a seguir.

\subsection{CARACTERIZAÇÕES DO WET-BLUE}

O resíduo de wet-blue é obtido na etapa de uniformização da espessura do couro em uma máquina denominada rebaixadeira. 0 processo de rebaixe do couro gera cerca de $375 \mathrm{~kg}$ de farelos e/ou pós de wet-blue (HU, 2011).

O resíduo foi caracterizado por meio de análises físico químicas descritas na Tabela 1:

\begin{tabular}{cccc} 
Tabela 1: Caracterização físico-química do resíduo de couro wet-blue cromad \\
\hline Parâmetro & Unidade & Norma & Ano \\
\hline Cálcio & $\%$ & NBR 13732 & 2013 \\
Cifra Diferencial & - & NBR 11057 & 2006 \\
Matéria volátil & $\%$ & NBR 11029 & 2013 \\
pH & - & NBR 11057 & 2006 \\
Extraíveis em Diclorometano & $\%$ & NBR 11030 & 2012 \\
Nitrogênio & $\%$ & ASTM D2868-17 & 2017 \\
Óxido de cromo & $\% \mathrm{Cr}_{2} \mathrm{O}_{3}$ & NBR 11054C & 2007 \\
\hline
\end{tabular}

Fonte: Autor ( 2020)

\subsection{ENSAIO PILOTO}

0 experimento foi realizado em um conjunto de fulões de aço inox 7way, com capacidade para 5 kg. Os parâmetros para execução do piloto foram baseados em estudos existentes (LONGHI, 2018; SCOPEL 2018; OLIVEIRA, 2007; HIJAZIN, 2003), já apresentados no referencial teórico deste artigo e em resultados prévios obtidos nos ensaios de bancada.

Os parâmetros adotados para a execução da hidrólise são apresentados na Tabela 2. 0 ensaio variou a forma de lavagem (em bancada e em fulão), a razão molar cromo:ácido (1:3 e 1:4) e o ajuste do pH (3,5 e 6 ). 


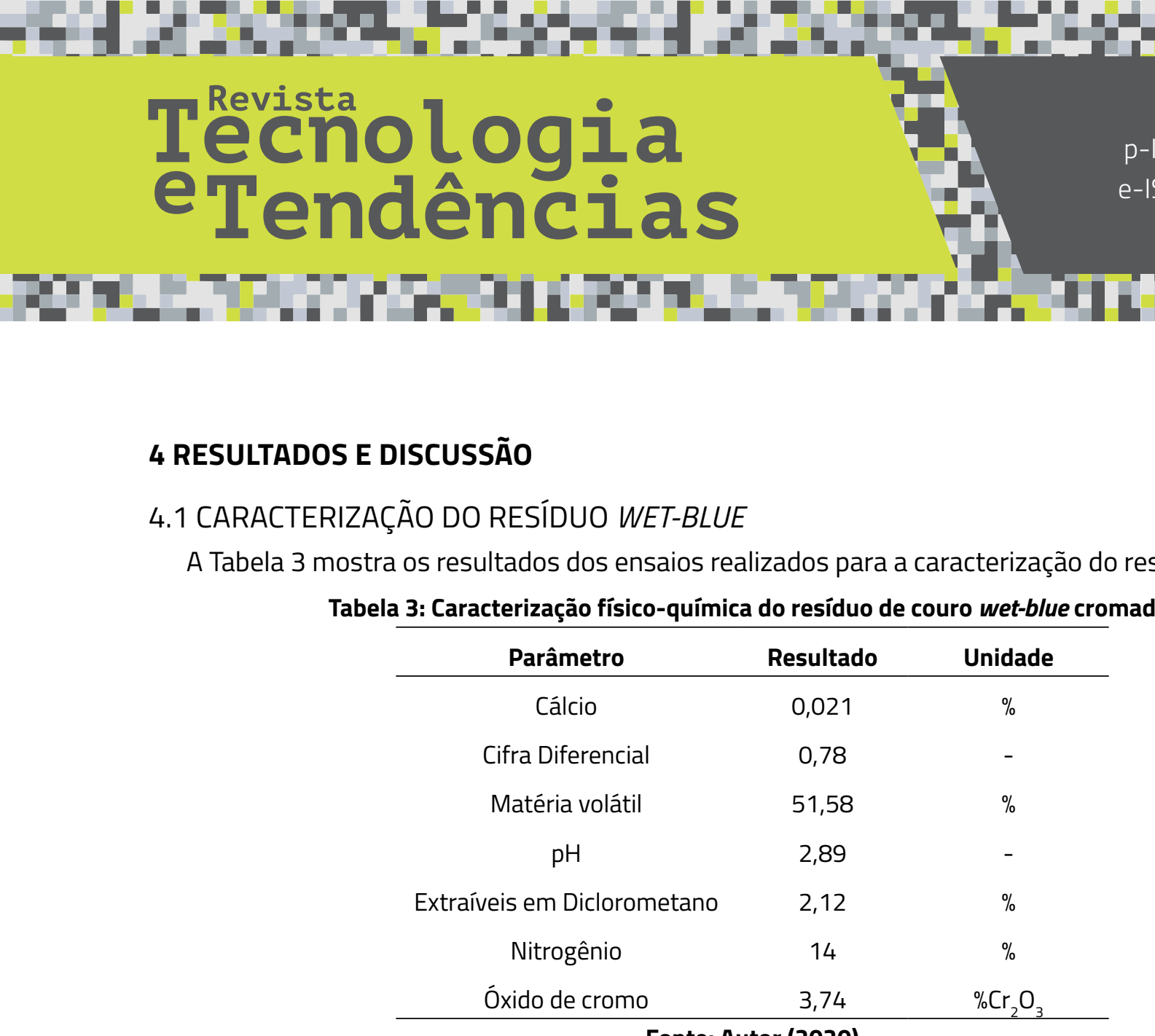

Fonte: Autor (2020)

0 resíduo de wet-blue analisado apresentou características próprias do couro curtido ao cromo, os valores analisados utilizaram como referência a NBR 13525 Ensaios físicos e químicos em couro - valores orientativos para aceitação de couros (ABNT, 2016).

A análise de nitrogênio apresentou uma concentração de $14 \%$ de $N_{2}$. Como pode ser observado na Tabela 4, o valor é compatível com os valores referenciados na literatura.

A concentração de $\mathrm{Cr}_{2} \mathrm{O}_{3}$ (óxido de cromo), presente no couro curtido é relevante uma vez que o óxido de cromo é o agente curtente utilizado na etapa de curtimento. A análise por EAAC (espectrofotômetro de absorção atômica) apresentou uma concentração de 3,74\% de $\mathrm{Cr}_{2} \mathrm{O}_{3}$ (óxido de cromo), o equivalente a 25.579,00 mg de cromo III. Segundo Mähler (1999) o percentual de óxido de cromo na serragem de rebaixadeira varia entre 3,6 a 4,6\%. Já a NBR 13525 (ABNT, 2016) determina que o valor deve estar acima de $3.5 \%$. A Tabela 4 mostra os resultados encontrados por autores que realizaram a caracterização do couro wet-blue. 


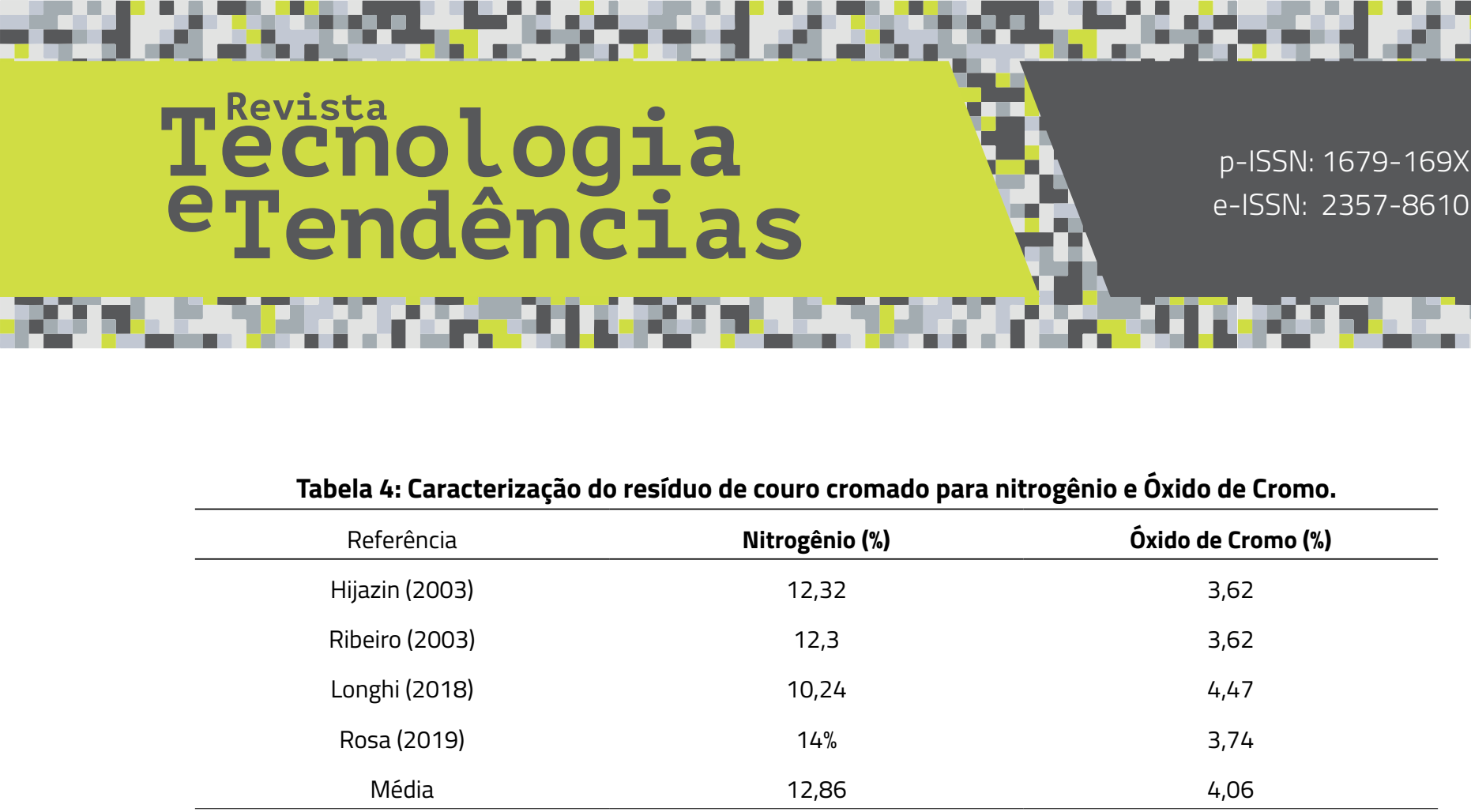

Fonte: Autor (2020)

\subsection{DESCROMAGEM WET- BLUE}

O processo de hidrólise do wet-blue resultou em dois produtos: 1) um sólido (colágeno) e 2) efluente líquido (banho) denominado de SCE (Solução de cromo extraído).

\subsubsection{Análises do Colágeno dos ensaios de Bancada}

Como pode ser observado na Tabela 5, as amostras de colágeno hidrolisado que possuem maior redução de cromo apresentam uma coloração mais clara em relação às amostras com menor redução.

Verificou-se também que as amostras lavadas em bancada apresentaram fibras menos desnaturadas em relação as amostras lavadas em fulão. Isto pode ser justificado através da associação de dois fatores: 1) temperatura de lavagem do fulão de $50^{\circ} \mathrm{C} ; 2$ ) ação mecânica no interior do fulão. Enquanto no colágeno puro a desnaturação ocorre próxima a $60^{\circ} \mathrm{C}$, o colágeno curtido resiste a temperaturas superiores a 130 'C (COVINGTON et al., 2009). No entanto, para operações de hidrólise com ácidos orgânicos, Brown et a (1986) menciona que temperaturas superiores a $70^{\circ} \mathrm{C}$ podem promover a gelatinização do colágeno.

Tabela 5: Resultados do processo de hidrólise no colágeno: amostras dos testes piloto 3

\begin{tabular}{cccccc}
\hline $\begin{array}{c}\text { Amostra } \\
\text { Unidade }\end{array}$ & $\begin{array}{c}\text { Relação } \\
\text { Cr:Ácido }\end{array}$ & $\mathrm{pH}$ & $\begin{array}{c}\text { Colágeno } \\
\left(\mathrm{Cr} \mathrm{mg.kg}^{-1}\right)\end{array}$ & $\begin{array}{c}\text { Colágeno Redução } \\
\text { do cromo \% }\end{array}$ & $\begin{array}{c}\text { Colágeno } \\
\% \mathrm{~N}_{2}\end{array}$ \\
\hline PIL3-65-1B & $1: 3$ & 6 & 5958,28 & 76,72 & 10,26 \\
PIL3-65-2B & $1: 4$ & 6 & 5530,09 & 78,39 & 9,98
\end{tabular}




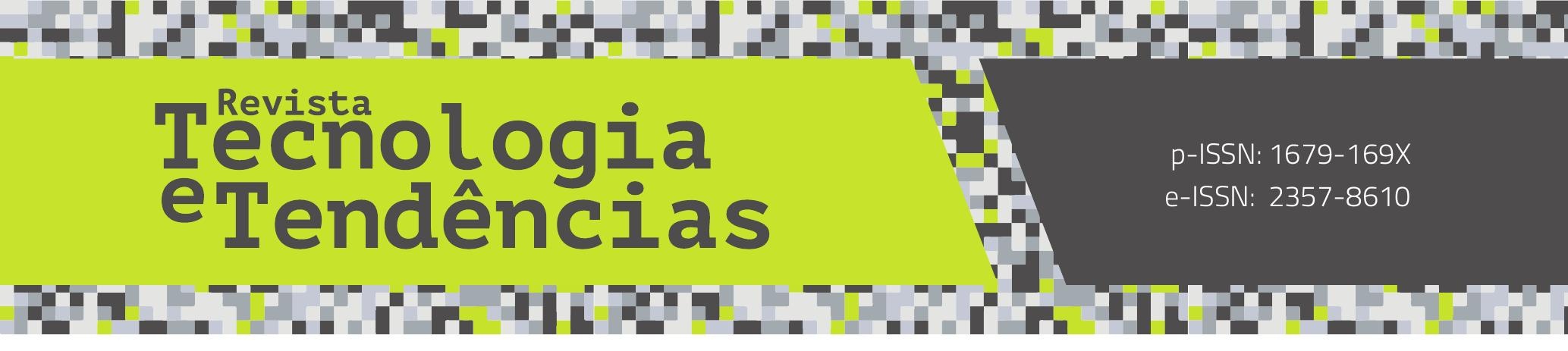

\begin{tabular}{|c|c|c|c|c|c|}
\hline PIL3-65-3B & $1: 3$ & 3,5 & 6521,46 & 74,52 & 10 \\
\hline PIL3-65-4B & $1: 4$ & 3,5 & 3237,86 & 87,35 & 9,53 \\
\hline PIL3-65-5F & $1: 3$ & 6 & 5822,45 & 77,25 & 6,93 \\
\hline PIL3-65-6F & $1: 4$ & 6 & 5457,75 & 78,67 & 5,17 \\
\hline PIL3-65-7F & $1: 3$ & 3,5 & 5135,89 & 79,93 & 9 \\
\hline PIL3-65-8F & $1: 4$ & 3,5 & 4292,28 & 83,23 & 9,7 \\
\hline
\end{tabular}

\section{Fonte Autor, 2020}

Como pode ser observado na Figura 3 os ensaios apresentaram uma eficiência na extração do cromo, similar ou inferior a literatura (LONGHI 2018; BROW, 1986, HIJAZIN, 2003; OLIVEIRA, 2007). Brow (1986) promoveu a hidrólise utilizando ácido cítrico, nas condições: proporção de Cr:Ligante de 1:4; temperatura de $70^{\circ} \mathrm{C}$, tempo de agitação 3 horas e pH próximo de 6 e obteve uma eficiência de extração de cromo para 87\%. Hijazin (2003) também realizou o teste em bancada nas condições: proporção de Cr:Ligante de 1:4,temperatura de $70^{\circ} \mathrm{C}, \mathrm{pH} 7$, sem agitação, e obteve uma extração de $87,24 \%$, resultado próximo ao encontrado no piloro PIL3-65-3-4B. 


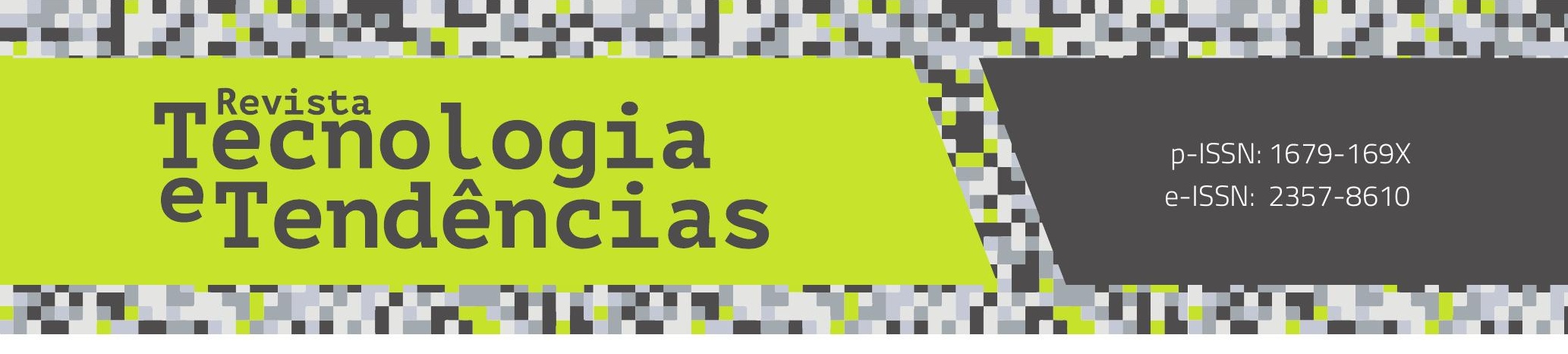

Figura 3: Percentual de redução de cromo no wet-blue teste piloto e literatura.

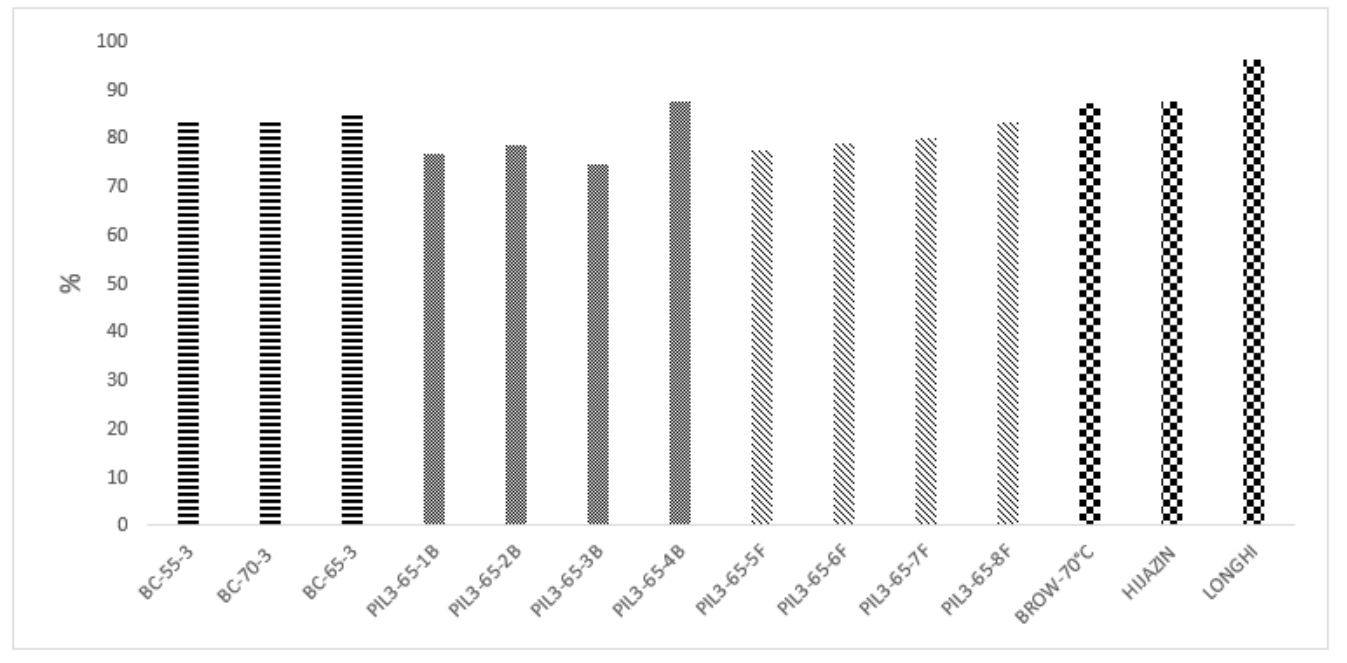

Fonte: Autor (2020)

Os resultados das amostras de bancada e piloto são inferiores aos obtidos por Longhi (2018), que alcançou uma extração de $95,94 \%$ em ensaios de bancada, utilizando como parâmetros: proporção (massa wet-blue:ácido cítrico) 1:3, 3 horas de agitação, temperatura de $55^{\circ} \mathrm{C}$, massa de resíduo $5 \mathrm{~g}$ wetblue, resíduo cominuído e emprego de centrifugação no processo de filtração.

Os resultados sugerem que a moagem do resíduo e o processo de centrifugação podem ter contribuído positivamente para melhora na eficiência da extração do cromo. No experimento realizado por Ribeiro (2003), o resíduo cominuído apresentou uma eficiência 13\% superior ao mesmo processo com resíduo sem cominuição. Isto ocorre, pois, o grão menor possibilita um aumento da área de contato superficial e uma maior interação do agente ácido com o colágeno.

Os resultados apontam que é difícil avaliar a influência das variáveis isoladamente, visto que foram obtidos resultados similares com emprego de diferentes parâmetros. Fica evidente que o processo de extração ocorre por meio de uma complexa sinergia promovida pela interação das diversas variáveis empregadas no processo de hidrólise.

Entre os autores apresentados neste capítulo Loghi (2018) foi quem obteve a melhor eficiência no processo de extração, 95,94\% ou seja o cromo remanescente no resíduo wet-blue é de 1.239,39 mg.kg-1, enquanto que o ensaio PIL3-65-3 4B apresentou o melhor resultado do experimento com uma eficiência de extração de $87,35 \%$ ou um resíduo com 3.237,86 mg.kg-1 de cromo remanescente.

Os valores encontrados nos experimentos ainda não são suficientes para caracterizar o wet-blue hidrolisado como resíduo não perigoso. De acordo com o CONAMA 420 (2009) que estabelece critérios 


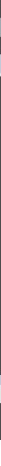

para caracterização de resíduos sólidos, o resíduo de couro wet-blue, será classificado como não perigoso se ao final da hidrólise a concentração máxima de cromo for inferior $400 \mathrm{mg} \cdot \mathrm{kg}^{-1}$. Isso significa que para obter uma concentração de 400 mg.kg-1 em um resíduo de couro com 4\% de óxido de cromo é necessário que se obtenha uma eficiência na extração de $98,53 \%$. Assim ajustes são necessários para que a hidrólise com emprego do ácido cítrico, seja de fato uma solução viável na transformação do resíduo de wet-blue em um resíduo não perigoso ou para a sua utilização como matéria prima para outros segmentos.

\subsubsection{Análises do Colágeno dos ensaios de Bancada}

Ao observar visualmente os banhos durante o processo de hidrólise foi possível constatar que a coloração se apresentou escura e uniforme após uma hora de agitação em todos os ensaios realizados. A Tabela 6 apresenta a concentração de cromo remanescente nos banhos considerando o efluente da hidrólise mais água de lavagem.

As amostras do banho do ensaio Piloto apresentaram uma concentração de cromo que variou entre 412,35 mg.kg-1 e 555,85 mg. kg-1. No banho residual da hidrólise de bancada realizada por Longhi (2018) identificou-se uma concentração de cromo equivalente a $600 \mathrm{mg} . \mathrm{Kg}^{1}$, o que representa $0,06 \%$ da massa total do wet-blue analisado. Os valores encontrados no experimento, são próximos do valor encontrado por Longhi (2018), mas apontam que a quantidade de cromo é insuficiente para o emprego na etapa de curtimento sendo necessário o aporte de aproximadamente $4 \%$ de óxido de cromo para o curtimento. Em formulações convencionais são utilizados, normalmente, 6\% de sulfato básico de cromo (AQUIM et al., 2019). 


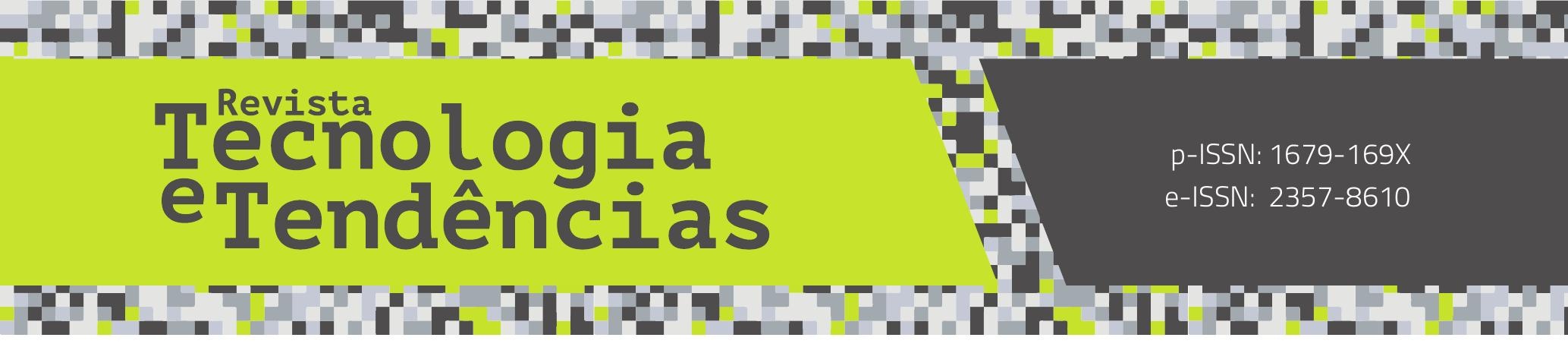

Tabela 6 Concentração de cromo e pH do banho: bancada e piloto 3

\begin{tabular}{|c|c|c|c|}
\hline Amostra Unidade & Banho SCE (Cr mg L-1) & $\mathrm{pH}$ & SCE Imagem \\
\hline PIL3-65-1B & 412,35 & 6,0 & \\
\hline PIL3-65-2B & 443,35 & 6,0 & \\
\hline PIL3-65-3B & 498,1 & 3,5 & \\
\hline PIL3-65-4B & 506,95 & 3,5 & \\
\hline PIL3-65-5F & 424,35 & 6,0 & \\
\hline PIL3-65-6F & 489,95 & 6,0 & \\
\hline PIL3-65-7F & 554,8 & 3,5 & \\
\hline PIL3-65-8F & 555,85 & 3,5 & \\
\hline
\end{tabular}

Fonte: Autor ( 2020)

Quanto ao pH da SCE, de acordo com a NBR 11057 - Determinação do pH e da cifra diferencial (ABNT, 2006), nas etapas de curtimento o pH do banho deve ser maior que 3,5. Sendo assim o banho 


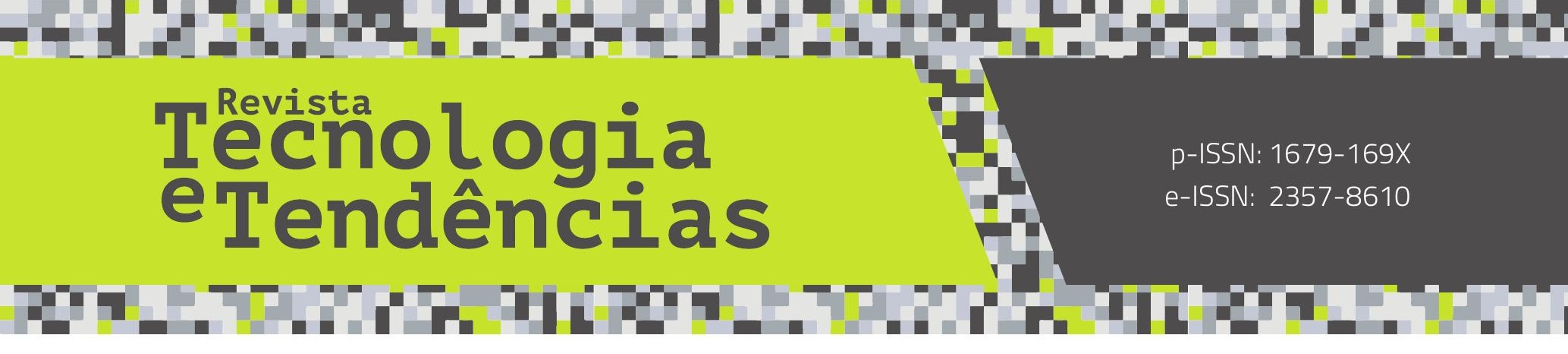

obtido na hidrólise pode ser utilizado sem a necessidade de ajustes uma vez que ao término do processo apresentou pH 3,5 e 6,0.

\section{CONSIDERAÇõES FINAIS}

Ao replicar o experimento utilizando os parâmetros definidos na literatura foi possível comprovar que a hidrólise é uma solução a ser considerada para a redução da concentração de cromo em resíduos de wet-blue. $O$ ácido cítrico se mostrou como um bom reagente para a promoção da hidrólise, no entanto, 0 método empregado ainda não foi suficiente para caracterizar o resíduo como não perigoso.

O colágeno obtido possui potencial para ser empregado como fertilizante, pois apresenta concentração de nitrogênio suficiente para atender a demanda de nitrogênio de diversas culturas, além de características que contribuem para a retenção de umidade e liberação lenta e gradual de nutrientes. No entanto, ajustes são necessários para reduzir a concentração de cromo a níveis que atendam às exigências da legislação brasileira para formulação de condicionadores de solo ou fertilizantes.

Quanto ao emprego do banho resultante da hidrólise, pode-se concluir que o mesmo apresentou um baixo percentual de cromo, mas, ainda assim, revela potencial para ser utilizado no processo de curtimento por propiciar o reúso da água de lavagem e por resultar em consumos menores de ácido e curtente.

\section{REFERÊNCIAS}

ABREU, Miriam Antônio de. Reciclagem do Resíduo de Cromo da Indústria do Curtume como

Pigmentos Cerâmicos. São Paulo. 2006. Tese (Doutorado em Engenharia Metalúrgica) - Escola Politécnica da Universidade de São Paulo, Universidade de São Paulo. São Paulo, 2006.

AllCA. Associación de Investigación de lãs Industrias del Curtido y Anexas. Proyecto Planta Tratamiento Rebajaduras Wet-blue. 2006.

AMARAL, Luciani Alano. Alternativas para o tratamento de resíduos de couro curtido ao cromo: hidrólise enzimática e ação bacteriana. 2008. Dissertação (Mestrado em Engenharia Química) Programa de Pós-Graduação em Engenharia Química, Universidade Federal do Rio Grande do Sul. Porto Alegre, 2008. 


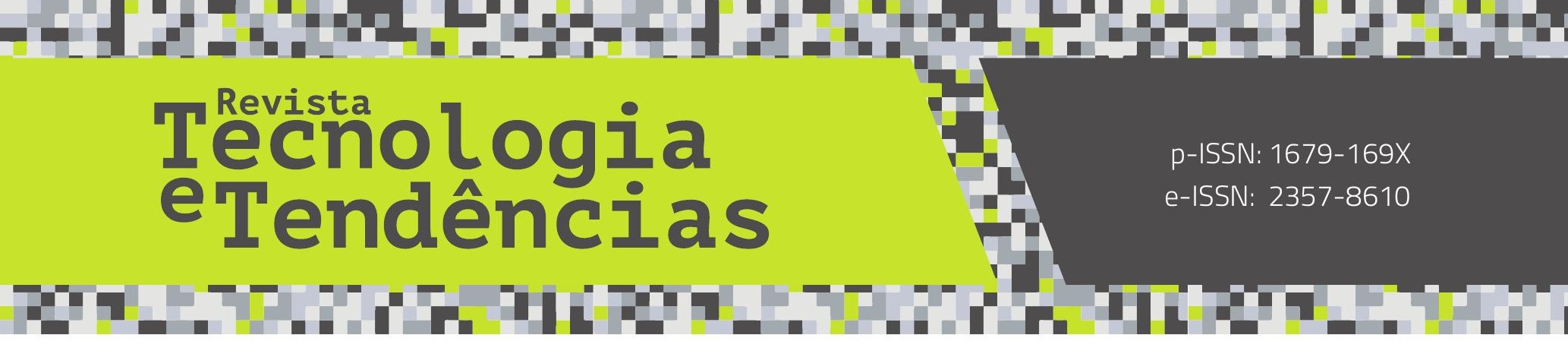

BRASIL. LEI N 12.305, DE 2 DE AGOSTO DE 2010. Institui a Política Nacional de Resíduos Sólidos PNRS, Brasília, DF, ago. 2010.

BROWN, D.A. et al. Investigation of hidroxamic acids for the extraction of chromium (III) from leather waste and the possible re-use of the extracted chromium in the tanning industry. Environmental Technology Letters, v. 7, p. 283-288, May. 1986.

BRUNS, Leandro. Estudo de extrações sequenciais de cromo em resíduos sólidos do processamento de couro. 41 p. Monografia (Curso de Bacharelado em Química), Departamento de Química, Universidade Federal de Santa Catarina, Florianópolis, 2004.

CABEZA, L. F. et al. Processing of leather waste: pilot scale studies on chrome shavings. Isolation of potentially valuable protein products and chromium. Waste Manage. (Oxford) 9, pp. 211-218, 1998.

CABEZA, L. F.; et al. Chemical modification of protein products isolated from chromium-containing solid tannery waste and resultant influence on physical and funcional properties. Journal of the American Leather Chemists Association, Cincinnati, Ohaio - USA, vol. 94, n.5, p.171-181, julho/1999.

COELHO, Livia Cristina et al. Resíduo de curtumes como fonte de nitrogênio para trigo e arroz em sucessão. Revista Brasileira de Ciência do Solo, v. 39, n. 5, p. 1445-1455, 2015.

COELHO, Maria Alice Zarur; SALGADO, Andrea Medeiros; RIBEIRO, Bernardo Dias. Tecnologia enzimática. Editora EPUB, 2008.

CONAMA - CONSELHO NACIONAL DO MEIO AMBIENTE. Resolução n 420, de 28 de dezembro de 2009. Diário Oficial [da] República Federativa do Brasil, Poder Executivo, Brasília, DF, 30 dez. 2009. Seção 1, p. 81-84

COT, J. et al. Waste processing in the tannery: production of gelatin, reconstituted collagen and glue from chrome-tanned leather splits and trimmings subjected to a modified detanning process. Journal of the

Society of Leather Technologists and Chemists, 1986.

COT J. et al. Processing of collagenic residues Isolation of gelatina by the action of peroxocromates.

Journal of the American Leather Chemists Association, v. 94, p. 115-127, 1999.

COVINGTON, Anthony D. Tanning chemistry: the science of leather. Londres: Royal Society of Chemistry, 2009. 


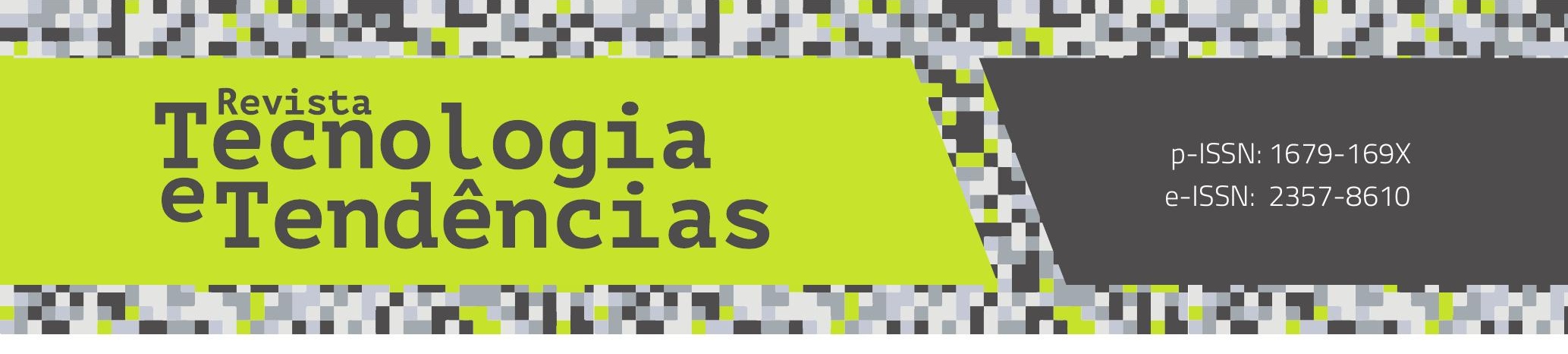

GARCIA, Nelissa G. Descontaminação do resíduo industrial de couro: uma proposta para o desenvolvimento sustentável nos curtumes. São Paulo. 2015. Dissertação (Mestrado em Ciência e Tecnologia de Materiais) - Programa de Pós-Graduação em Ciência e Tecnologia de Materiais, Universidade Estadual Paulista. Presidente Prudente, 2015.

HIJAZIN, Carlos Atalla Hidalgo. Descromagem ácida de resíduos de couro (serragem de rebaixadeira). Rio Grande do Sul. 2003. Dissertação (Mestrado em Engenharia) - Programa de Pós-Graduação em Engenharia de Minas, Metalúrgica e dos Materiais, Universidade Federal do Rio Grande do Sul. Porto Alegre, 2003.

$\mathrm{HU}$, Jing et al. Ecological utilization of leather tannery waste with circular economy model. Journal of Cleaner Production, v. 19, n. 2-3, p. 221-228, 2011.

KOLOMAZNIK, K., et al..; Experience in industrial practice of enzymatic dechromation of chrome shavings, Journal of American Leather Chemists Association, v.95, p.55-63, 2000.

LONGHI, Elisandra Menegat. Obtenção de Nutrientes para Plantas Oriundos de Resíduo de Couro. Rio Grande do Sul. 2018. Dissertação (Mestrado Profissional em Tecnologia de Materiais e Processos Industriais) - Programa de Pós-Graduação em Tecnologia de Materiais e Processos Industriais, Universidade Feevale. Novo Hamburgo, 2018.

MÄHLER, A. P. D. Descromagem hidrometalúrgica de resíduos sólidos (serragem) de couro. Rio Grande do Sul, 1999. Dissertação (Mestrado em Engenharia) - Programa de Pós-Graduação em Engenharia de Minas, Metalúrgica e dos Materiais, Universidade Federal do Rio Grande do Sul. Porto Alegre, 1999.

MALEK, Ammar; HACHEMI, Messaoud; DIDIER, Villemin. New approach of depollution of solid chromium leather waste by the use of organic chelates: economical and environmental impacts. Journal of hazardous materials, v. 170, n. 1, p. 156-162, 2009.

METZ, Lisiane Emilia Grams. Avaliação ambiental dos resíduos sólidos oriundos da produção de couros no Rio Grande do Sul. Rio Grande do Sul. 2016. Dissertação (Mestrado em Engenharia Civil) Programa de Pós-Graduação em Engenharia Civil, Universidade do Vale do Rio dos Sinos. São Leopoldo, 2016. 


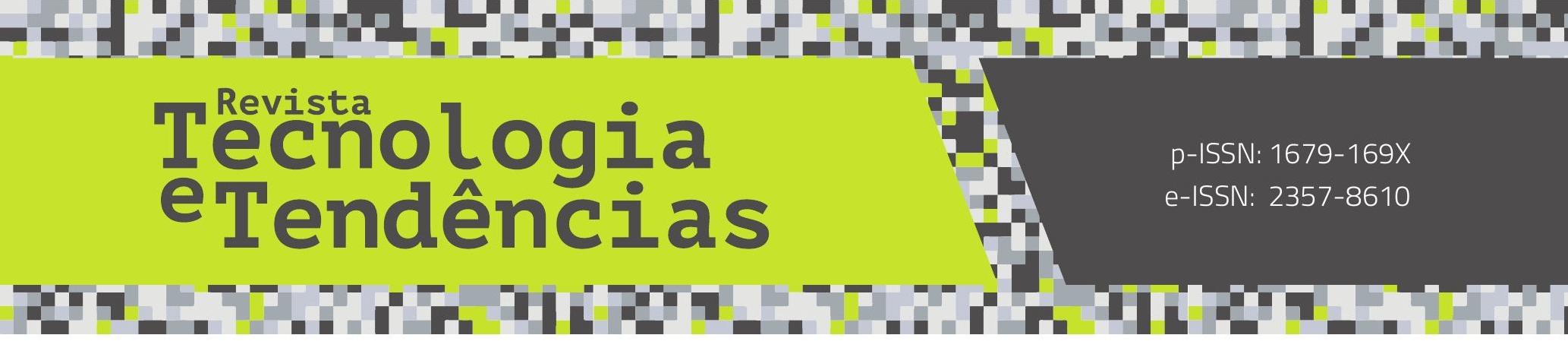

MOKREJS, Pavel et al. Properties of Collagen Hydrolyzates Obtained from Leather Shavings. Asian Journal of Chemistry, v. 19, n. 2, p. 1207, 2007.

O COURO E O CURTUME BRASILEIRO. In: CICB. Centro das indústrias de curtume do Brasil. Brasília, [2017?]. Disponivel em: <http://www.cicb.org.br/cicb>. Acesso em: 01 de jul de 2019.

OLIVEIRA, Quintão Lima de. Tratamento de rejeitos sólidos contendo cromo da indústria de couro: uso em processo de adsorção e como fonte de nitrogênio na agricultura. Minas Gerais. 2007. Dissertação (Mestrado em Agroquímica) - Programa de Pós-Graduação em Agroquímica, Universidade de Lavras. Lavras, 2007.

RIBEIRO, Karen Cristina Rodenbusch. Hidrólise de resíduos de couro curtido ao cromo. Rio Grande do Sul. 2003. Dissertação (Mestrado em Engenharia) - Programa de Pós-Graduação em Engenharia de Minas, Metalúrgica e dos Materiais, Universidade Federal do Rio Grande do Sul. Porto Alegre, 2003.

RIEHL, Alice. Caracterização de resíduos de couro provenientes de um aterro industrial. Rio Grande do Sul. 2015. Dissertação (Mestrado em Engenharia Civil) - Programa de Pós-Graduação em Engenharia Civil, Universidade do Vale do Rio dos Sinos. São Leopoldo, 2015.

SCOPEL, B.S. et al. Hydrolysis of Chromium Tanned Leather Waste: Turning Waste into Valuable Materials - A Review. The journal of the american leather chemists association, n.113, p. 122-130. 2018.

SCOPEL, B. S. et al. . Collagen Hydrolysate Extraction from Chromed Leather Waste for Polymeric Film Production. JOURNAL OF THE AMERICAN LEATHER CHEMISTS ASSOCIATION, v. 111, p. 30-40, 2016.

SILVA, C. A. J.; Pfeiter, R.; Enzimas em la Industria del Cuero - Revisión de conceptos, tipos de aplicación y resultados prácticos. Buckman laboratórios Ltda. 2005.

SILVA, R. C. DA et al. POTENCIALIDADES NUTRICIONAIS DE RESÍDUOS DE COURO WET-BLUE PARA A ALIMENTAÇÃO DE RUMINANTES. Ciência Animal Brasileira, p. 847-852, 2009.

SIMIONI, T.; DETMER, A. Pirólise de resíduo de couro curtido ao cromo em reator de leito fluidizado. Blucher Chemical Engineering Proceedings, v. 1, p. 7706-7713, 2014. 


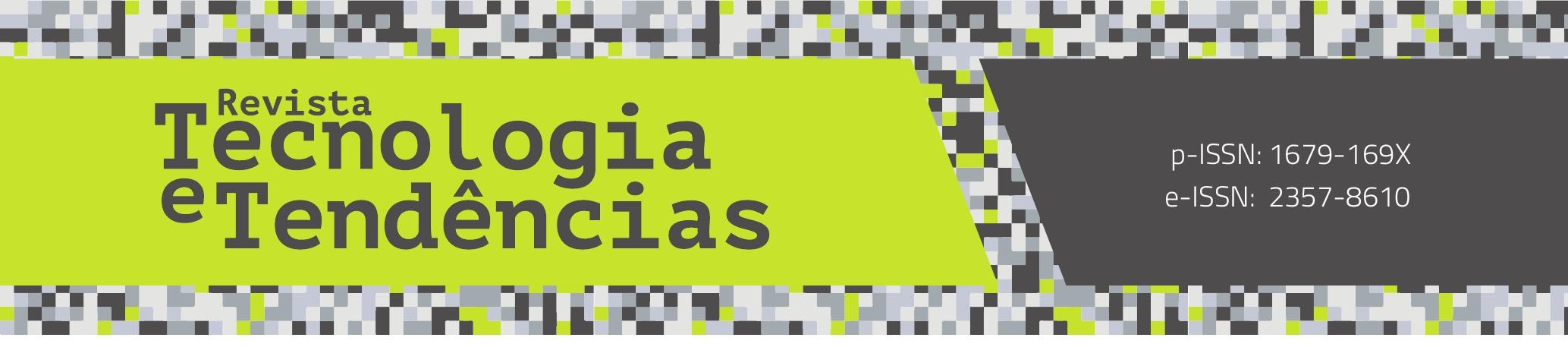

SUNDAR, V. John et al. Recovery and utilization of chromium-tanned proteinous wastes of leather making: A review. Critical Reviews in Environmental Science and Technology, v. 41, n. 22, p. 20482075, 2011.

TAHIRI et al. . Extraction of proteins from chrome shavings with sodium hidroxide and reuse of chromium in the tanning process. JOURNAL OF THE AMERICAN LEATHER CHEMISTS ASSOCIATION, v. 99, p. 16-25, 2004.

TAYLOR, M. M. et al., Processing of leather waste: Pilot sacale studies on chrome shavings. Part I isolation and characterization of protein products and separations of chrome cake. Journal of American Leather Chemists Association, v.93, p.61-82 - 1998. 